https://doi.org/10.48009/1_iis_2006_362-366

\title{
DEVELOPING SUSTAINABLE DIGITAL OPPORTUNITY: THE CASE OF LALASHAN DOWEB MODEL
}

\author{
Su-Houn Liu, Chung Yuan Christian University, vandy@ mis.cycu.edu.tw \\ Yu-Hsieh Sung, RDEC, The Executive Yuan, yhsung@ redc.gov.tw \\ Hsiu-Li Liao, Chung Yuan Christian University, wenlly@mis.cycu.edu.tw
}

\begin{abstract}
Much time and money has been committed by Taiwan governments over the last 5 years in establishing opportunities for underserved populations to gain access to IT and the Internet in an effort to overcome the so-called "digital divide"[9]. This article traces the efforts of a government-supported project that establish a sustainable EC model at a remote area (Lalashan) in Taiwan. In this cases, technical inspiration and innovation are closely married to eco-social inspiration and innovation in order to gradually combine and balance between profit making and public welfare.
\end{abstract}

Keywords: Digital Divide, Digital Opportunity, Electronic Business, DOWEB Model

\section{BACKGROUND}

The last half of the twentieth century was marked by steady advanceS in the ubiquity of information and communication technologies (ICTs) throughout the world. Digital divide was first discussed in a report by the U.S. Department of Commerce. The term refers to the gaps that exist between groups regarding their ability to use information and communication technologies effectively, and these groups differ in wealth acquisition due to different levels of literacy and technical skills $[1,2,4]$. According to a previous study [6], the number of the Taiwanese accessing the Internet has grown rapidly in recent years; yet, in the midst of this general expansion, the "digital divide" between information "haves" and "have-nots" continues to widen. A number of the Taiwanese, living in remote areas, are lagging behind the national average in computer literacy and Internet access, regardless of income level. According to studies conducted by the Research, Development, and Evaluation Commission of Taiwan [7],

- At almost every income level, the households in remote areas are less likely to own computers than those in country or urban areas.

- At every income level, the households in remote areas are significantly less likely to have home
Internet access than those in country or urban areas.

Indigenous families in remote areas are 50\% less likely to own a computer than the average family and are far less likely to access the Internet than the average family.

\section{LALASHAN: THE HOMETOWN OF PEACHES}

Lalashan (Mt. Lala) is situated in the only indigenous people township (Fusing Township) of Taoyuan County. It is located in the most remote area of Fusing Township (Figure 1). The total population is 2,200 and over $80 \%$ of the residents are indigenous people. Lalashan means "beautiful mountain" in indigenous language. Lalashan is regarded as the hometown of peaches in Taiwan. The peach from Lalashan, sweet and delicious, is a classic fruit of Taiwan Island; peach selling is the main income source for most of the households in this area [8].

Although the Lalashan peach is well recognized by many Taiwanese as one of the most delicious peaches around the island, peach selling was a very unstable income source. For example, in August 2000 , peach price was down sharply due to an abundant harvest. The profit was less than expected. In that year the average income for each household was just NT $\$ 200,000$. Forty percent of the households, mainly indigenous families, were below poverty line. Most of the households were thinking about switching to another line of business due to the unstable income associated with growing peaches. 


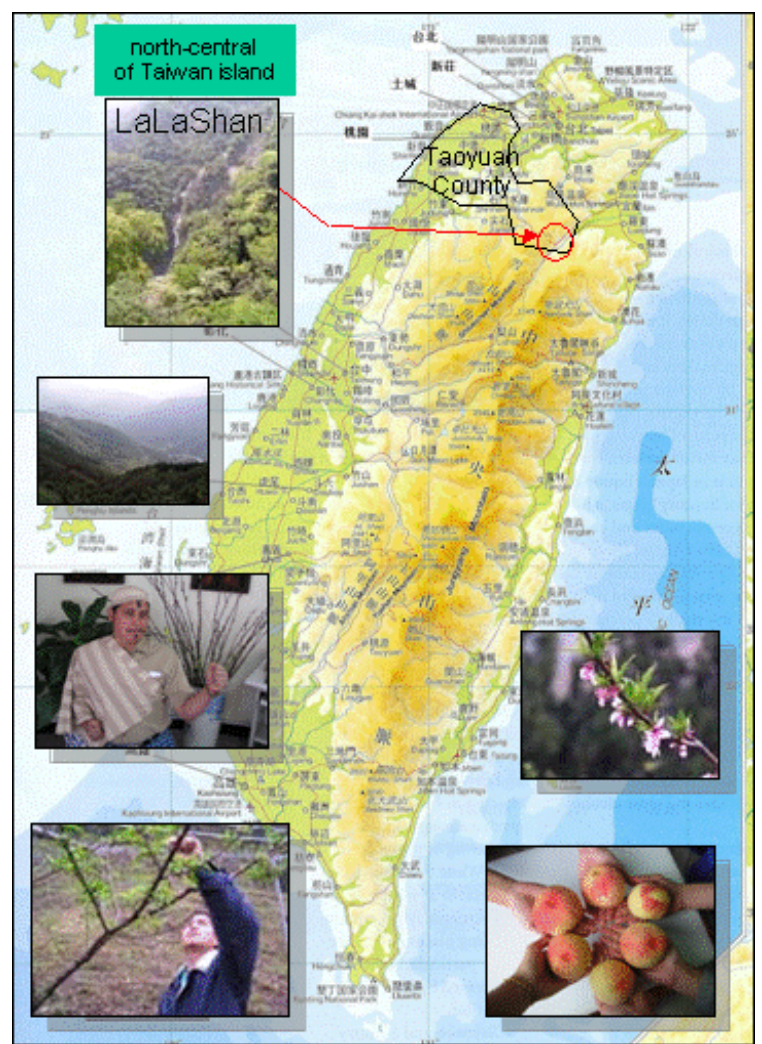

Figure 1. Lalashan, Taoyuan, Taiwan

\section{Digital Opportunity for Lalashan Farmers}

In the year of 2003, a group of students from the Department of Information Management, Chung Yuan Christian University, was sent into the Lalashan area to study the predicament of these Lalashan farmers. In the students' report, they summarized four main reasons for the unstable income:

(1) Growing peaches is not easy, and the best harvest time for high quality peaches is very short. Also, much care must be taken to store and preserve peaches. Only half to $70 \%$ of the peaches produced each season can be sold out in time.

(2) High delivery costs lowers actual income. For each box with a total value of NT\$500, the delivery cost is around NT $\$ 200$ to NT $\$ 300$.

(3) Farmers are not willing to produce high quality fruit. Much extra effort is needed to produce better quality peaches, but that effort may not necessarily result in better peach prices.

(4) Farmers have to compete with imported goods. Lower-priced peaches imported from other places compete with Lalashan peaches in the market. Some peaches were falsely marked as Lalashan peaches.
After investigating the reasons causing the predicament for Lalashan farmers, the students suggested selling peach through Internet. This suggestion was based on the following reasons:

- Selling online means no inventory. Possible loss is decreased.

- Selling online lets customers enjoy the freshest peaches.

- Selling online decreases the delivery cost by eliminating the intermediary.

- The direct sale model establishes a direct connection between farmers and their consumers and encourages farmers to care about product quality.

- Selling online helps compete with counterfeits.

But in the year 2003, promoting the peaches by Ecommerce as a digital opportunity for the Lalashan peach farmers was almost a mission close to impossible. Most of them knew little about computers and the Internet. In other words, to promote by E-commerce for these Lalashan peach farmers, the first thing that had to be done was to bridge their digital divide. In the year of 2003, a government-supported project, aimed at bridging the digital divide, was launched in this area. A comprehensive approach called DOWEB (Digital Opportunity Within E-business) model was applied to cross through the Digital Divide. In the rest of this paper, we illustrate the DOWEB model, which has been employed in Lalashan. In this case, technical inspiration and innovation are closely married to eco-social inspiration and innovation in order to gradually combine and balance between profit making and public welfare.

\section{LALASHAN DOWEB PROJECT}

\section{Project Mission}

Turn those peach farmers in Lalashan into the pioneers of e-commerce

\section{Project Strategies}

Strategy 1: Find out Life Improvement Applications

The government first invested much money and manpower to set up the information system and facilities. The information resources of the elementary schools in Lalashan were open to the local residents to use. Chung Yuan Christian University offered free lessons of computer and the Internet. At the start, the farmers were not enthusiastic about it. But after the project team 
decided to sell their peaches online in 2004 and promised at least a sales value of NT\$3,000,000, then the farmers were convinced and started to engage in the business. The project team then realized that the key to bridging the digital divide was to create the demands for information technology instead of just providing information systems and training.

\section{Strategy 2: Integrate Government Resources}

In order to integrate government resources, two government agencies were assigned to coordinate the Lalashan DOWEB project. One of the coordinating agencies was the Research, Development, and Evaluation Commission of the central government; another one was the local Taoyuan County Government. More than 8 government projects were integrated to provide basic facilities, training or electronic business services in this project (Figure 2).

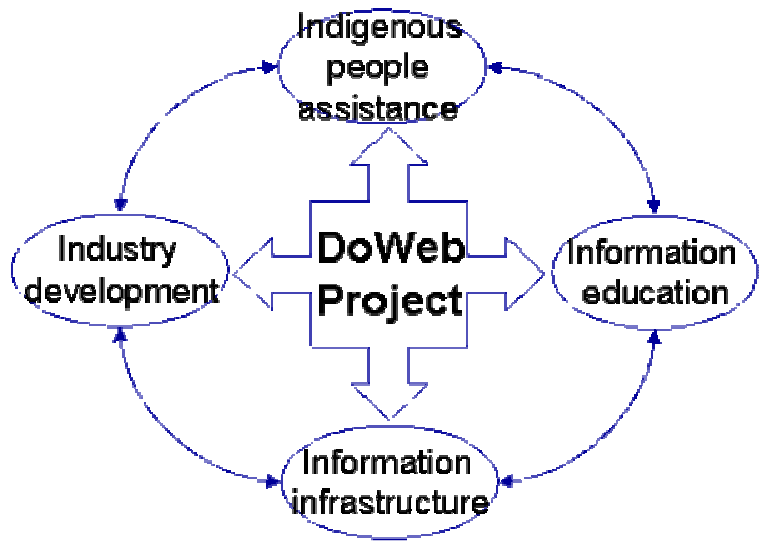

Figure 2. Integrate Government Resources

\section{Strategy 3: Set up an Information Service Station}

In 2002, Taoyuan County Government together with the Ministry of Education brought optical fiber to the elementary schools in Lalashan. A computer classroom was installed in each of the two schools in Lalashan. A tribe information station was launched in August 2004 to provide easy access for the adults. Eventually, most of the Lalashan households owned their own computers, which were all connected to the Internet via broadband. The major role of those local information service stations then became education centers. The teachers and students from Chung Yuan Christian University and other institutions came to Lalashan to offer information training. Nowadays, those stations offer Internet summer camps for kids, night classes for adults and e-commerce courses during peach-selling season.

Strategy 4: Link up with Local Resources

Local resources provided valuable contribution for our project. Two local resources were invited into the project. They were the local tourism business enterprises and religious groups (churches). With higher levels of literacy and technical skills, local tourism business enterprises shared the broadband with the farmers and offered integration in operation and created profit for all the parties. Since most peach farmers are pious Christians, the support from churches encouraged them to continually keep up their efforts, and the project has now become a business of the whole Lalashan community.

\section{Strategy 5: Collaborate with Private Groups}

Lalashan Website (www.lalasun.com.tw, Figure 3) was built and maintained by the volunteers from the Digital Opportunity and Care Office, Department of Information Management, Chung Yuan Christian University. The students from CYCU built the web pages, and enterprises such as Chung-Hwa Motor, Quanta Computer, Compal Computer, SOGI.com, Premier Inc, etc. provided resources to support the operations of the website. Several welfare groups, such as the Aboriginal Community University, Yiren Foundation, and the Rotary Club of Taoyuan-Tashih, also devoted lots of manpower and funds to support this project.

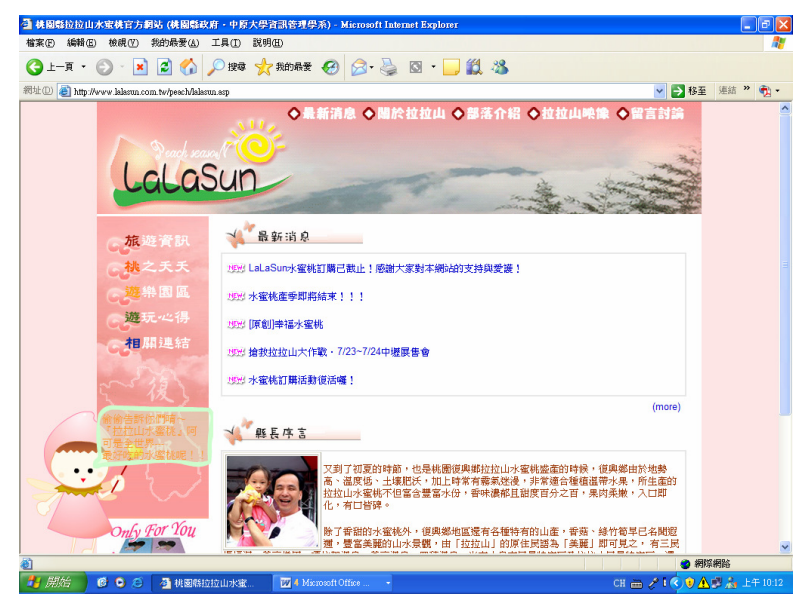

Figure 3. www.lalasun.com.tw 


\section{CURRENT STATUS}

After two and a half years of hard work, the achievements of Lalashan DOWEB project has been far beyond everybody's expectations. In August 2000, the average income for each household in Lalashan area was about NT\$200,000 per year. Among them, $40 \%$ of the households, mainly indigenous families, were below poverty line. Most of the households knew little about computers and the Internet. But in the year 2005, the Lalashan community has been selected as one of the Ecommerce and digital opportunity benchmarking communities in Taiwan. Today, $80 \%$ of Lalashan households own computers, and most of the computers are connected to the Internet via broadband. The Lalashan children were the winners of the Silver Award in The 2005 International Schools Cyberfair Award. A total of 91 Lalashan farmers sell their peaches online and generated a total sales value of NT\$12,000,000 in 2005. Also, most of the farmers' average income has been doubled in 2005 in comparison with the year 2000.

What have we learned from DOWEB project? In order to construct a sustainable business model that can bridge the digital divide, the following critical factors should be fulfilled:

- The key is to create demands for information technology instead of just to provide facilities and training.

- The project needs efforts from both the communities and families. The engagements and involvements from civil and social groups work the best to bridge the digital divide.

- Leveraging digital opportunity needs not only training but also integrated plans.

- The project not only offers fair opportunities to all the groups involved but also stimulates the farmers' productivity and their income with a leap.

- To bridge the digital divide, governments, enterprises, schools and public welfare groups must collaborate and play their parts duly and properly.

\section{CONCLUSION}

To bridge the digital divide, we need to offer access to information technology. This means creating a fair digital opportunity for everyone by removing the restrictions of region, education, and economic status, etc. After examining our efforts undertaken in the Lalashan DoWeb project, the observations can be summarized briefly as follows:

(1) Projects should be sustainable in the long run. To empower people and to reduce the digital divide, the nature of the project should be sustainable in long terms. Economically responsible projects such as our BPT Program are already proving more successful than charitable or free models [5]. Such programs provide digital opportunities that can improve life quality; moreover, they can bring sustainable development to the people and the whole society.

(2) ICT service should be owned and participated by the local community in general

As we have already noticed in the DOWEB project, "humans are created from their families and always have a desire to belong to groups." We notice that people devote themselves when they are working with other family or community members. Projects that can follow the local needs and content are essential—top down approaches do not work [3].

\section{REFERENCES}

1. Hopkins, L. (2005). Making a community network sustainable: The future of the wired high rise, Information Society, 21(5), 379.

2. Koss, F.A. (2001) Children falling into the digital divide. Journal of International Affairs, 55(1), 75-90.

3. Kvasny, L. \& Keil, M. (2006). The challenges of redressing the digital divide: A tale of two US cities, Information Systems Journal, 16(1), 23.

4. Mistry, J.J.. (2005). A conceptual framework for the role of government in bridging the digital divide, Journal of Global Information Technology Management, 8(3), 28-46.

5. Rao, S.S. (2003). Information systems in Indian rural communities. The Journal of Computer Information Systems, 44(1), 48.

6. Research, Development, and Evaluation Commission. (2004). Bridging Digital Divide web-site, http://www.digitaldivide.nat.gov.tw/

7. Research, Development, and Evaluation Commission, (2004) Report on National Digital Divide, RDEC, The Executive Yuan.

8. Liu, S.H. (2005). Project Report on Lalashan Blissful Peach Program, Department of Information Management, Chung Yuan Christian University.

9. The Executive Yuan. (2002). Challenge 2008: The Six-year National Development Plan, http://www.gio.gov.tw/taiwan-website/4oa/20020521/2002052101.htm 